\title{
BMJ Open Optimal plateau pressure for patients with acute respiratory distress syndrome: a protocol for a systematic review and meta-analysis with meta- regression
}

\author{
Hideto Yasuda, ${ }^{1,2}$ Tetsuro Nishimura, ${ }^{3}$ Tetsuro Kamo, ${ }^{4}$ Masamitsu Sanui, ${ }^{5}$ \\ Eishu Nango, ${ }^{6}$ Takayuki Abe, ${ }^{2,7}$ Toru Takebayashi, ${ }^{2}$ Alan Kawarai Lefor, ${ }^{8}$ \\ Satoru Hashimoto ${ }^{9}$
}

To cite: Yasuda H, Nishimura T, Kamo T, et al. Optimal plateau pressure for patients with acute respiratory distress syndrome: a protocol for a systematic review and meta-analysis with meta-regression. BMJ Open 2017;7:e015091. doi:10.1136/ bmjopen-2016-015091

Received 10 November 2016 Revised 17 January 2017 Accepted 27 March 2017

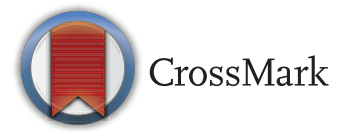

For numbered affiliations see end of article.

Correspondence to Prof. Satoru Hashimoto; satoru@koto.kpu-m.ac.jp

\section{ABSTRACT}

Introduction Lower tidal volume ventilation in patients with acute respiratory distress syndrome (ARDS) is a strategy to reduce the plateau pressure and driving pressure to limit ventilator-induced lung injury (VILI). Several randomised controlled trials (RCTs) and metaanalyses showed that limiting both the plateau pressure and the tidal volume decreased mortality, but the optimal plateau pressure to demonstrate a benefit is uncertain. The aim of this systematic review is to investigate the optimal upper limit of plateau pressure in patients with ARDS to prevent VILI and improve clinical outcomes using metaanalysis with and without meta-regression.

Methods and analysis RCTs comparing two mechanical ventilation strategies will be included, with lower plateau pressure and with higher plateau pressure, among patients with ARDS and acute lung injury. Data sources include MEDLINE via the NCBI Entrez system, Cochrane Central Register of Controlled Trials (CENTRAL), EMBASE and Ichushi, a database of papers in Japanese. Two of three physicians will independently screen trials obtained by search for eligibility, and extract data from included studies onto standardised data recording forms. For each included trial, the risk of bias and the quality of evidence will be evaluated using the Grading of Recommendation Assessment Development and Evaluation system. Ethics and dissemination This study does not require ethical approval. The results of this systematic review and meta-analysis with and without meta-regression will be disseminated through conference presentation and publication in a peer-reviewed journal.

Trial registration number CRD42016041924

\section{INTRODUCTION}

Acute respiratory distress syndrome (ARDS) is a common life-threatening disorder in critically ill patients with $30 \%-60 \%$ mortality. ${ }^{1-3}$ ARDS is usually accompanied by shortterm and long-term morbidities including prolonged stay in the intensive care unit, prolonged ventilator dependence, various

\section{Strengths and limitations of this study}

- One strength of this study is that it is a systematic review with meta-regression analysis comparing different plateau pressures to investigate the upper limit of plateau pressure for patients with acute respiratory distress syndrome undergoing mechanical ventilation.

- One limitation of the study is the paucity of available data regarding the transpulmonary pressure although it is also important to compare the transpulmonary pressure in addition to the plateau pressure. We have to wait for future available studies.

- This is a protocol article. The results of the subsequent systematic review and meta-analysis with meta-regression analysis will be prepared separately.

neuropsychological impairments (eg, depression, cognitive decline) and decreased quality of life. $^{245}$

The most critical factor associated with the high mortality in patients with ARDS is ventilator-induced lung injury (VILI) ${ }^{6}$ although VILI can also develop in patients with non-injured lung. ${ }^{7}$ Patients with ARDS and low lung compliance receiving mechanical ventilation (MV) may develop VILI, including regional alveolar overdistension, repetitive cycling alveolar collapse with shear stress (atelectrauma) aggravated by a high concentration of inspired oxygen. ${ }^{8-11}$ VILI can lead to an extended time needed for liberation from MV and an increase in mortality.

For the purpose of minimising VILI, a substantial number of ventilator strategies have been proposed. ${ }^{12-19}$ Lower tidal volume $(6 \mathrm{~mL} / \mathrm{kg}$ per predicted body weight) ventilation is a strategy to reduce plateau pressure 
and driving pressure, roughly reflecting the level of alveolar overdistension. ${ }^{14}$ Several randomised controlled trials (RCTs) and meta-analyses have shown a beneficial effect of pressure and volume-limited ventilation strategies on clinical outcomes in patients with ARDS. ${ }^{14} 15$ 20-27 In the Scandinavian clinical practice guideline 2014, ${ }^{21}$ developed with a Cochrane systematic review, ${ }^{20}$ it is strongly recommended that airway pressure and tidal volume should be limited. In the Surviving Sepsis Campaign Guideline $2012,{ }^{28}$ it is recommended that plateau pressure should be measured and maintained below $30 \mathrm{cmH}_{2} \mathrm{O}$ during the time of passive pulmonary expansion. However, Villar et $a l^{19}$ have recently reported in an observational study that a platerau pressure above $26 \mathrm{cmH}_{2} \mathrm{O}$ is harmful, which suggests that appropriate plateau pressure still remains to be investigated.

However, the Cochrane review ${ }^{20}$ was a comparison between two lung ventilation strategies, protective and non-protective, not a comparison of different cut-off limits of plateau pressures. All RCTs included in the meta-analysis ${ }^{16}$ performed a comparison of higher and lower levels of the upper limits of plateau pressures, but no studies compared various levels of plateau pressures. Also, interactions between the time course and changes in plateau pressure were not considered in the meta-analysis. ${ }^{16}$ Furthermore, the relationship between the plateau pressure and mortality in ARDS may not be linear, ${ }^{29}$ it may be difficult to investigate the optimal upper limit of plateau pressure by a simple comparison of two different plateau pressures. Therefore, to investigate the optimal upper limit of plateau pressure during the course of ARDS, a simple meta-analysis of RCTs seems to be insufficient. Stratification by the upper limit of plateau pressure and by the day on ventilators along with regression analysis using a meta-regression analysis may be effective.

\section{OBJECTIVE}

The objective of this systematic review is to investigate the optimal limit of plateau pressure on a different day on ventilators to improve clinical outcomes associated with VILI in patients with ARDS.

\section{METHODS AND ANALYSES}

This systematic review is designed following the Preferred Reporting Items for Systematic review and Meta-Analyses (PRISMA) statements (see online supplementary material). ${ }^{30}$ The logistics and reporting of this protocol will be in compliance with the PRISMA-P. This protocol is registered with PROSPERO prospective register of systematic reviewers (registration number: CRD42016041924).

\section{STUDY ELIGIBILITY}

\section{Type of studies}

We will include only published RCTs, either full scale or as pilot studies.

\section{Type of participants}

The study will include adults with ARDS or acute lung injury (ALI) from any cause, as defined by the North-American-European Consensus Conference on ARDS, aged 18 years or older, undergoing MV. ${ }^{31}$

Type of interventions and comparators: We will include RCTs which compared two different MV strategies, with a lower plateau pressure and a higher plateau pressure, among patients with ARDS and ALI. We will conduct subgroup analyses of the plateau pressures stratified by the day of measuring plateau pressure in addition to a primary meta-analysis which does not consider ventilator day.

\section{Type of outcomes}

The following outcome measures will be evaluated: the primary outcome is short-time mortality $((1)$ at the end of the follow-up period for each trial, (2) at day 28, and (3) at the hospital discharge), and secondary outcomes are the number of ventilator-free days up to 28 days and barotrauma during hospitalisation.

\section{INFORMATION SOURCES}

We searched MEDLINE via the NCBI Entrez system, the Cochrane Central Register of Controlled Trials (CENTRAL), EMBASE and Ichushi, a database including papers in Japanese.

\section{SEARCH STRATEGY}

We used the search keywords 'Mechanical ventilation' AND 'ARDS', 'adult respiratory distress syndrome', 'ALI' or 'acute lung injury' AND 'tidal volume', 'pressure limited' or 'volume limited'. We also performed a $\mathrm{MeSH}$ term search using the following terms: 'respiratory distress syndrome, adult', or 'acute lung injury' AND 'tidal volume', or 'respiration, artificial'. Searches were performed in May or June 2016. The detailed strategy and details of the dates performed are shown in table 1.

\section{Study records and data management}

The literature search results from each database will be extracted into Microsoft Excel files and duplicates will be removed by being sorted alphabetically based on author. The results of all processes (first screening and second screening) are recorded to the same data file. All full-text files will be managed with EndNote (X7) bibliographic software (Thompson Reuters, Philadelphia, Pennsylvania, USA). A meta-analysis will be conducted with the Review Manager (RevMan) software V.5.3.5. All data will be managed by the primary investigator HY.

\section{Selection process}

Two of three physicians (HY, TN, TK) will screen titles and abstracts during the first screening and the full text during the second screening for relevant studies, and will independently extract data from included studies into standardised data forms. Disagreements are resolved by 
Table 1 Search strategy

\section{Number}

1. MEDLINE (performed on 17 May 2016)

Component 1. Included patients

\begin{tabular}{|c|c|}
\hline$\# 1$ & $\begin{array}{l}\text { Respiratory distress syndrome, adult[MH] OR shock lung } \\
\text { OR acute respiratory distress syndrome OR adult respiratory } \\
\text { distress syndrome }\end{array}$ \\
\hline \#2 & $\begin{array}{l}\text { Acute lung injury[MH] OR Acute lung injury OR Acute lung } \\
\text { injuries }\end{array}$ \\
\hline \#3 & ARDS OR ALI \\
\hline \#4 & \#1 OR \#2 OR \#3 \\
\hline \#5 & Tidal volume[MH] OR Tidal volumes OR Tidal volume \\
\hline \#6 & $\begin{array}{l}\text { Respiration, Artificial[MH] OR Artificial respiration OR } \\
\text { Mechanical ventilation OR Mechanical ventilations }\end{array}$ \\
\hline$\# 7$ & 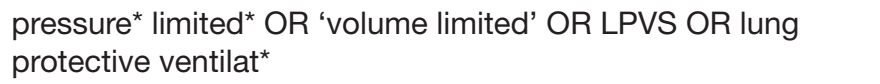 \\
\hline \#10 & $\begin{array}{l}\text { Clinical trial[pt] OR trial[ti] OR randomised controlled trial[pt] } \\
\text { OR(controlled clinical trial[pt] OR randomised[tiab])OR } \\
\text { placebo[tiab] OR clinical trials as topic[MH] OR randomly[tiab] }\end{array}$ \\
\hline$\# 11$ & Animals[MH] NOT (Animals[MH] AND Humans[MH]) \\
\hline$\# 12$ & \#10 NOT \#11 \\
\hline \#13 & \#9 AND \#12 \\
\hline \multicolumn{2}{|c|}{ 2. CENTRAL (performed on 17 May 2016) } \\
\hline \multicolumn{2}{|c|}{ Component 1. Included patients } \\
\hline$\# 1$ & $\begin{array}{l}\text { MeSH descriptor: [Respiratory Distress Syndrome, Adult] } \\
\text { explode all trees }\end{array}$ \\
\hline \multicolumn{2}{|c|}{ Component 2. Ventilator strategies } \\
\hline \#7 & MeSH descriptor: [Tidal Volume] explode all trees \\
\hline \#8 & artificial near ventilation \\
\hline \#9 & tidal volume \\
\hline \#10 & protective near ventilation \\
\hline$\# 11$ & pressure-limited \\
\hline$\# 12$ & LPVS \\
\hline \#13 & $\# 7$ or \#8 or \#9 or \#10 or \#11 or \#12 \\
\hline \#14 & \#6 and \#13 \\
\hline \multicolumn{2}{|c|}{ 3. EMBASE (performed on 20 June 2016) } \\
\hline \multicolumn{2}{|c|}{ Component 1. Included patients } \\
\hline$\# 1$ & $\begin{array}{l}\text { EMB.EXACT('adult respiratory distress syndrome') OR ('shock } \\
\text { lung' OR 'human ARDS' OR 'acute respiratory distress } \\
\text { syndrome' OR 'adult respiratory distress syndrome') }\end{array}$ \\
\hline
\end{tabular}

Continued

\section{Searched for}




\begin{tabular}{|c|c|}
\hline Number & Searched for \\
\hline \#2 & $\begin{array}{l}\text { EMB.EXACT('acute lung injury') OR ('acute lung injuries' OR } \\
\text { 'acute lung injury') }\end{array}$ \\
\hline \#3 & TI,AB(ARDS) OR TI,AB(ALI) \\
\hline \#4 & \#1 OR \#2 OR \#3 \\
\hline \#5 & $\begin{array}{l}\text { EMB.EXACT.EXPLODE('tidal volume') OR ('tidal volumes' OR } \\
\text { 'tidal volume') }\end{array}$ \\
\hline \#6 & $\begin{array}{l}\text { EMB.EXACT.EXPLODE('artificial ventilation') OR ('artificial } \\
\text { respiration' OR 'mechanical ventilation' OR 'mechanical } \\
\text { ventilations') }\end{array}$ \\
\hline \multicolumn{2}{|c|}{ Component 3. Study design } \\
\hline \#10 & $\begin{array}{l}\text { (EMB.EXACT('controlled clinical trial') OR EMB.EXACT. } \\
\text { EXPLODE('clinical trial (topic)') OR EMB.EXACT('randomized } \\
\text { controlled trial')) OR (TI,AB(randomized) OR TI,AB(randomly) } \\
\text { OR TI(trial) OR TI,AB(placebo)) }\end{array}$ \\
\hline$\# 11$ & \#9 AND \#10 \\
\hline \multicolumn{2}{|c|}{ Component 4. Language limit } \\
\hline \#12 & \#11 NOT (ANIMAL(YES) NOT HUMAN(YES)) \\
\hline \#13 & \#12 AND PD(>=20150401) \\
\hline \multicolumn{2}{|c|}{ Component 2. Ventilator strategies } \\
\hline \#4 & 一回換気量/TH or 一回換気量/AL \\
\hline \#5 & $\begin{array}{l}\text { 人工呼吸/TH or 人工呼吸/AL or レスピレータ装/AL or 機械的換 } \\
\text { 気/AL or 人工換気量/AL or 人工呼吸管理/AL or 人工呼吸法/AL } \\
\text { or 人工呼吸療法/AL or 調節呼吸/AL }\end{array}$ \\
\hline \#6 & $\begin{array}{l}\text { 人エ呼吸器/TH or 人エ呼吸器/AL or ベンチレータ/AL or ベンチ } \\
\text { レーター/AL or レスピレータ/AL or レスピレーター/AL or 機械 } \\
\text { 的ベンチレータ/AL or 機械的ベンチレーター/AL or 肺ベンチレ } \\
\text { ータ/AL or 肺ベンチレーター/AL }\end{array}$ \\
\hline$\# 7$ & \#4 or \#5 or \#6 \\
\hline \#8 & \#3 and \#7 \\
\hline
\end{tabular}

ALI, acute lung injury; ARDS, acute respiratory distress syndrome; LPVS, lung protective ventilation strategy.

discussion with one of the three physicians who did not screen the study. EN supervises the process of systematic review. TA supervises the process of analysis as a biostatistician. MS, TT and SH are consultants on clinically relevant issues.

\section{Data collection process}

After extracting studies for meta-analyses during the second screening, data will be extracted from each study by three reviewers (HY, TN, TK) using two tools ${ }^{1}$ : the Cochrane Data Collection Form (RCTs only) ${ }^{32}$ and $^{2}$ Review Manager (RevMan) software V.5.3.5 . $^{33}$

Risk of bias in individual studies

The risk of bias in each included study will be evaluated with the Cochrane Risk of Bias Assessment tool ${ }^{34} 35$ with respect to the following seven domains: (1) random sequence generation, (2) allocation concealment, (3) 
blinding of participants and personnel, (4) blinding of outcome assessors, (5) incomplete outcome data, (6) selective outcome reporting and (7) other sources of bias. Each bias will be graded as either 'low-risk,' 'unclear-risk' or 'high-risk.' Two of three reviewers (HY, TN, TK) will separately grade the bias of each study, and any disagreement will be resolved by a decision from the remaining reviewer.

\section{Data synthesis}

Forest plots will be used for the meta-analysis, and effect size will be expressed as relative risk with $95 \%$ CI for categorical data and as weighted mean differences with 95\% CI for continuous data. Outcome measures will be pooled using a random effect model to take into account study-specific effects in measures. For all analyses, a two-sided $p$ value $<0.05$ is considered significant. In case of missing data, we will attempt to contact the authors of the study for additional data. If a reply from the authors is not obtained, we will classify it as missing data.

Meta-regression analysis will be conducted to evaluate the association between outcome measures and covariates, and to determine the cut-off of the plateau pressure affecting the outcomes adjusted with covariates, such as the different kinds of ventilation methods, the day of plateau pressure measurement and severity of ARDS for the evaluation. Meta-regression analysis will be performed with R V.3.3.2.

\section{Assessment of heterogeneity}

Study heterogeneity between trials for each outcome will be assessed with an $\mathrm{I}^{2}$ statistic for quantifying inconsistency (RevMan). $\mathrm{I}^{2}$ values of $<25 \%, 25 \%-50 \%$ and $>50 \%$ represent small, medium and large amounts of heterogeneity, respectively. ${ }^{36}$ Subgroup analysis, meta-regression analysis and sensitivity analysis will be performed for evaluating possible sources of heterogeneity when sufficient data are available.

\section{Assessment of reporting bias}

A funnel plot will be used to investigate the possibility of publication bias if $\geq 10$ studies are available (RevMan). ${ }^{37}$ To test for funnel plot asymmetry, we will use the Egger test $^{38}$ for continuous outcomes and the arcsine test ${ }^{39}$ for dichotomous outcomes.

\section{Subgroup analysis and sensitivity analysis}

Subgroup analysis is planned based on the main factors that may cause heterogeneity, which are the levels of plateau pressure. Subgroup analysis will also be performed for different timing of plateau pressure measured during MV. We are also planning subgroup analyses after stratification according to ventilator strategies and modes.

For sensitivity analysis, we will first exclude all studies that are assessed as having a high risk of bias. High risk of bias in each study will be determined when the quality of evidence of each study will be assessed as 'low' or 'very low.' The remaining studies will be used for sensitivity analysis.

\section{Assessment of confidence in cumulative evidence}

We will evaluate the quality of evidence for these studies using the Grading of Recommendation Assessment Development and Evaluation (GRADE) system. ${ }^{40}$ The quality of evidence will be decreased by any one of the following limitations: risk of bias, imprecision, inconsistency, indirectness and publication bias. Based on this assessment, the quality of evidence for each outcome will be assessed as 'high', 'moderate', 'low' or 'very low' (GRADEpro, McMaster University, 2014). Two of three reviewers (HY, $\mathrm{TN}, \mathrm{TK}$ ) will separately grade the quality of evidence of each study, and any disagreement will be resolved by a decision of the remaining reviewer.

\section{Author affiliations}

${ }^{1}$ Department of Intensive Care Medicine, Kameda Medical Center, Chiba, Japan ${ }^{2}$ Department of Preventive Medicine and Public Health, Keio University School of Medicine, Tokyo, Japan

${ }^{3}$ Traumatology and Critical Care Medical Center, Osaka City University Graduate School of Medicine, Osaka, Japan

${ }^{4}$ Department of Respiratory Medicine, Keio University School of Medicine, Tokyo, Japan

${ }^{5}$ Department of Anesthesiology and Critical Care Medicine, Jichi Medical University Saitama Medical Center, Saitama, Japan

${ }^{6}$ Department of General Medicine, Tokyo-Kita Medical Center, Tokyo, Japan ${ }^{7}$ Biostatistics Unit at Clinical and Translational Research Centre, Keio University Hospital, Tokyo, Japan

${ }^{8}$ Department of Surgery, Jichi Medical University, Tochigi, Japan ${ }^{9}$ Department of Anesthesiology and Intensive Care Medicine, Kyoto Prefectural University of Medicine, Kyoto, Japan

Contributors HY contributed in the study concept and design, screening for relevant studies, and drafting of the manuscript. TN and TK contributed to the study concept and design, screening for relevant studies. MS contributed to the study concept and design, and critical revision of the manuscript for important intellectual content. AKL contributed to critical revision of the manuscript for important intellectual content. EN supervised the process of systematic review. TA supervised the process of analysis as a biostatistician. TT, AKL and SH were consultants on clinically relevant issues.

Competing interests None declared.

Provenance and peer review Not commissioned; externally peer reviewed.

Open Access This is an Open Access article distributed in accordance with the Creative Commons Attribution Non Commercial (CC BY-NC 4.0) license, which permits others to distribute, remix, adapt, build upon this work non-commercially, and license their derivative works on different terms, provided the original work is properly cited and the use is non-commercial. See: http://creativecommons.org/ licenses/by-nc/4.0/

(c) Article author(s) (or their employer(s) unless otherwise stated in the text of the article) 2017. All rights reserved. No commercial use is permitted unless otherwise expressly granted.

\section{REFERENCES}

1. Rubenfeld GD, Caldwell E, Peabody E, et al. Incidence and outcomes of acute lung injury. N Engl J Med 2005;353:1685-93.

2. Rubenfeld GD, Herridge MS. Epidemiology and outcomes of acute lung injury. Chest 2007;131:554-62.

3. Bersten AD, Edibam C, Hunt T, et al. Incidence and mortality of acute lung injury and the acute respiratory distress syndrome in three Australian States. Am J Respir Crit Care Med 2002;165:443-8.

4. Herridge MS, Tansey CM, Matté A, et al. Functional disability 5 years after acute respiratory distress syndrome. N Engl J Med 2011;364:1293-304.

5. Davidson TA, Caldwell ES, Curtis JR, et al. Reduced quality of life in survivors of acute respiratory distress syndrome compared with critically ill control patients. JAMA 1999;281:354-60. 
6. Amato MB, Meade MO, Slutsky AS, et al. Driving pressure and survival in the acute respiratory distress syndrome. N Engl J Med 2015;372:747-55.

7. Sutherasan $Y$, Vargas M, Pelosi P. Protective mechanical ventilation in the non-injured lung: review and meta-analysis. Crit Care 2014;18:211.

8. Gattinoni L, Pesenti A, Avalli L, et al. Pressure-volume curve of total respiratory system in acute respiratory failure. computed tomographic scan study. Am Rev Respir Dis 1987;136:730-6.

9. Dreyfuss D, Soler P, Basset $\mathrm{G}$, et al. High inflation pressure pulmonary edema. Respective effects of high airway pressure, high tidal volume, and positive end-expiratory pressure. Am Rev Respir Dis 1988;137:1159-64.

10. Muscedere JG, Mullen JB, Gan K, et al. Tidal ventilation at low airway pressures can augment lung injury. Am J Respir Crit Care Med 1994;149:1327-34

11. Caironi P, Cressoni M, Chiumello D, et al. Lung opening and closing during ventilation of acute respiratory distress syndrome. Am J Respir Crit Care Med 2010;181:578-86.

12. Ferguson ND, Cook DJ, Guyatt GH, et al. High-frequency oscillation in early acute respiratory distress syndrome. $N$ Engl J Med 2013;368:795-805.

13. Young D, Lamb SE, Shah S, et al. High-frequency oscillation for acute respiratory distress syndrome. N Engl J Med 2013;368:806-13.

14. Brower RG, Matthay MA, Morris A, et al. Ventilation with lower tida volumes as compared with traditional tidal volumes for acute lung injury and the acute respiratory distress syndrome. $N$ Engl $\mathrm{J}$ Med 2000;342:1301-8.

15. Meade MO, Cook DJ, Guyatt GH, et al. Ventilation strategy using low tidal volumes, recruitment maneuvers, and high positive end-expiratory pressure for acute lung injury and acute respiratory distress syndrome: a randomized controlled trial. JAMA 2008;299:637-45.

16. Kacmarek RM, Villar J, Sulemanji D, et al. Open lung approach for the acute respiratory distress syndrome: a pilot, Randomized Controlled Trial. Crit Care Med 2016;44:32-42.

17. Fish E, Novack V, Banner-Goodspeed VM, et al. The esophageal Pressure-Guided ventilation 2 (EPVent2) trial protocol: a multicentre, randomised clinical trial of mechanical ventilation guided by transpulmonary pressure. BMJ Open 2014;4:e006356.

18. Talmor D, Sarge T, Malhotra A, et al. Mechanical ventilation guided by esophageal pressure in acute lung injury. N Engl J Med 2008;359:2095-104.

19. Villar J, Ambrós A, Soler JA, et al. Age, PaO2/FIO2, and Plateau pressure score: a proposal for a Simple Outcome score in patients with the Acute Respiratory distress syndrome. Crit Care Med 2016;44:1361-9.

20. Petrucci N, De Feo C. Lung protective ventilation strategy for the acute respiratory distress syndrome. Cochrane Database Syst Rev 2013:CD003844.

21. Claesson J, Freundlich M, Gunnarsson I, et al. Scandinavian clinical practice guideline on mechanical ventilation in adults with the acute respiratory distress syndrome. Acta Anaesthesiol Scand 2015;59:286-97.

22. Fuller BM, Mohr NM, Drewry AM, et al. Lower tidal volume at initiation of mechanical ventilation may reduce progression to acute respiratory distress syndrome: a systematic review. Crit Care 2013;17:R11.

23. Burns KE, Adhikari NK, Slutsky AS, et al. Pressure and volume limited ventilation for the ventilatory management of patients with acute lung injury: a systematic review and meta-analysis. PLoS One 2011;6:e14623.

24. Moran JL, Bersten AD, Solomon PJ. Meta-analysis of controlled trials of ventilator therapy in acute lung injury and acute respiratory distress syndrome: an alternative perspective. Intensive Care Med 2005;31:227-35.

25. Brochard L, Roudot-Thoraval F, Roupie E, et al. Tidal volume reduction for prevention of ventilator-induced lung injury in acute respiratory distress syndrome. The Multicenter Trail Group on Tidal Volume reduction in ARDS. Am J Respir Crit Care Med 1998;158:1831-8.

26. Brower RG, Shanholtz CB, Fessler HE, et al. Prospective, randomized, controlled clinical trial comparing traditional versus reduced tidal volume ventilation in acute respiratory distress syndrome patients. Crit Care Med 1999;27:1492-8.

27. Villar J, Kacmarek RM, Pérez-Méndez L, et al. A high positive endexpiratory pressure, low tidal volume ventilatory strategy improves outcome in persistent acute respiratory distress syndrome: a randomized, controlled trial. Crit Care Med 2006;34:1311-8.

28. Dellinger RP, Levy MM, Rhodes A, et al. Surviving Sepsis Campaign: international guidelines for management of severe Sepsis and septic shock, 2012. Intensive Care Med 2013;39:165-228.

29. Laffey JG, Bellani G, Pham T, et al. Potentially modifiable factors contributing to outcome from acute respiratory distress syndrome: the LUNG SAFE study. Intensive Care Med 2016;42:1865-76.

30. Shamseer L, Moher D, Clarke M, et al. Preferred reporting items for systematic review and meta-analysis protocols (PRISMA-P) 2015: elaboration and explanation. BMJ 2015;349:g7647.

31. Bernard GR, Artigas A, Brigham KL, et al. The American-European Consensus Conference on ARDS. definitions, mechanisms, relevant outcomes, and clinical trial coordination. Am J Respir Crit Care Med 1994;149:818-24.

32. Data collection Form-Intervention review for RCTs only. secondary data collection Form-Intervention review for RCTs only. http:// training.cochrane.org/resource/data-collection-forms-interventionreviews. (accessed 7 November 2016).

33. RevMan 5 download and installion. Secondary RevMan 5 download and installion. http://tech.cochrane.org/revman/download (accessed 7 Nov 2016).

34. Cochrane Handbook for Systematic Reviews of Interventions. http:// training.cochrane.org/handbook. (accessed 7 Nov 2016).

35. Cochrane Handbook for Systematic Reviews of Interventions. Table 8.5.d: criteria for judging risk of bias in the 'Risk of bias' assessment tool. http://handbook.cochrane.org/chapter_8/ table_8_5_d_criteria_for_judging_risk_of_bias_in_the_risk_of.htm (accessed 7 Nov 2016).

36. Higgins JP, Thompson SG. Quantifying heterogeneity in a metaanalysis. Stat Med 2002;21:1539-58.

37. Sterne JA, Sutton AJ, loannidis JP, et al. Recommendations for examining and interpreting funnel plot asymmetry in meta-analyses of randomised controlled trials. BMJ 2011;343:d4002.

38. Davey Smith G, Egger M. Meta-analyses of randomised controlled trials. Lancet 1997;350:1182.

39. Rücker G, Schwarzer G, Carpenter J. Arcsine test for publication Bias in meta-analyses with binary outcomes. Stat Med 2008;27:746-63.

40. Guyatt GH, Oxman AD, Schünemann HJ, et al. GRADE guidelines: a new series of articles in the Journal of Clinical Epidemiology. J Clin Epidemiol 2011;64:380-2. 